\title{
Aromatik Kokuların Bilişsel ve Duygusal Etkileri Üzerine Bir İnceleme
}

\author{
Arş. Gör. Cantürk AKBEN \\ Abant İzzet Baysal Üniversitesi, Fen-Edebiyat Fakültesi, Psikoloji Bölümü, Gölköy Yerleşkesi, \\ Bolu / Türkiye, akben@ hotmail.com, ORCID: 0000-0002-2001-2784
}

\section{Prof. Dr. Hamit COŞKUN}

Abant İzzet Baysal Üniversitesi, Fen-Edebiyat Fakültesi, Psikoloji Bölümü, Gölköy Yerleşkesi, Bolu / Türkiye, hamitcoskun2000@ gmail.com, ORCID: 0000-0002-5509-8717

\section{$\ddot{\mathbf{O} z}$}

İnsan yaşamında koku duyusu diğer duyulara göre daha az kullanılan bir duyudur. Psikoloji alanında da görsel, işitsel ve dokunmayla ilgili pek çok uyarıcı farklı amaçlarla kullanılırken, kokusal uyaranlar daha az çalışılmaktadır. Bu makalenin amacı psikoloji alanında koku değişkeninin davranışa olan etkisini araştıran çalışmaları incelemektir. Yapılan araştırmalar aromatik kokuların bellekte geri çağırmayı kolaylaştırdığını, duygudurumu olumlu etkilediğini, dikkati artırdığını ve yatıştırıcı etkilerinin olduğuna işaret etmektedir. Beyinde kokunun amigdala ve prefrontal korteksle ilişkili olduğu bulunmuştur. Bu makalede gelecek araştırmalara ışık tutulmaktadır.

Anahtar Kelimeler: Koku; Kokusal uyaranlar; Koku psikolojisi.

* Sorumlu Yazar. Tel: +90 3742541000 - 1310

(C) 2018 Kalem Eğitim ve Sağlık Hizmetleri Vakfı. Bütün Hakları Saklıdır. 


\title{
A Review on the Cognitive and Emotional Effects of
}

\section{Aromatic Odors}

\begin{abstract}
The sense of smell is used less than other senses in human life. Even though visual, auditory and tactile stimuli are largely examined in psychology literature, few studies, unfortunately, examine the influence of odor. The aim of this review was to examine studies related to the effects of aromatic odors on some behaviors. Studies have demonstrated that aromatic odors enhance retrieval of information, positive mood, and attention, and produce relieving effects. Amygdala and prefrontal cortex are related brain areas to aromatic odors. This study highlights some horizons for future studies.
\end{abstract}

Keywords: Odor; Olfactive stimulations; Psychology of odor.

\section{Extended Summary}

Many visual, auditory and even tactile stimuli are used and examined in psychological research. These stimuli are the display of various images, the completion of some tasks by hand, the examination of the effect of some voices on various tasks etc. Perhaps one of the least sought-after stimuli is olfactory stimuli as compared to others.

Our first aim in this study is to summarize the studies on olfactory stimuli in the literature and to identify the research needs in this area. In this context, one of the most important influences, the effects of smells on mood and well-being will be discussed. Then the second aim of this study is to explain the reasons of the difficulties of odor studies and to determine the methods that should be followed in new studies.

\section{Odor and Memory}

The ability to retrieve information from the memory can be considered as the most significant effect of odors. Odors can be used as a mnemonic, especially in autobiographical memory. (Chu and Downes, 2000, 2002; Rubin, Groth and Goldsmith, 1984). Daniels and Vermetten (2016) emphasize that the relation between odor and memory should be approached more emotionally. Newly learned information can be conditioned with odor besides retrieving old memories (Akben, 2015; Ritter, Strick, Bos, Van Baaren and 
Dijksterhuis, 2012).

Odors are an important stimulus in context-dependent memory (Chu and Downes, 2002; Ehrlichman and Halpern, 1988; Herz, 1997, 1998). According to this approach, environmental stimuli and information are stored in memory together then the environmental stimuli can be used as a clue for retrieving of information (Smith and Vela, 2001).

\section{Odor and Attention}

The odor-attention relation has not fully defined yet. Ilmberger, Heuberger, Mahrhofer, Dessovic, Kowarik and Buchbauer (2001) found that odors have no effect on attention and reaction time. Nevertheless, participants received odor evaluated themselves more successful. Millot, Brand and Morand (2002) observed a decrease in the response times of participants received positive and negative odors. In the study of Michael, Jacquot, Millot and Brand (2003), the effect of odors on short-term visual attention was investigated and found to vary with the characteristics of the odors.

\section{Odor and Brain Activation}

Seubert, Freiherr, Djordjevic and Lundström (2013) applied a metaanalysis of 45 studies on this field. According to the results, it was determined that the main areas relevant to odors are amygdala and orbitofrontal cortex. Activation-amygdala relation may explain the odor-emotion relation. However, activation of the orbitofrontal cortex may explain the effect of odor in cognitive performance tasks.

\section{Odor and Mood}

Orange and lavender have created a positive mood as well as decreased anxiety (Lehrner, Marwinski, Lehr, Johren and Deecke, 2005). Diego et al. (1998) also reported the relaxing effect of lavender. In a study by Lehrner, Eckersberger, Walla, Pötsch and Deecke (2000), it was found that orange scent had an anxiety-reducing effect on the patients and made the mood positive. Relaxing effect of lavender was shown in some other studies (Diego et al., 1998; Moss, Cook, Wesnes and Duckett, 2003; Ludwigson and Rottman, 1989). It is known that various moods (relaxed, calm, enthusiastic, sad ...) are influenced by different odors (vanilla, lavender, orange ...) in addition to these studies (Warrenburg, 2005). While lily of the valley can be comforting, mint flavor could be a more stimulating effect (Warm, Dember and Parasuraman, 
1991). In this context, the Geneva Emotion and Odor Scale (GEOS) was developed to measure the effects of odors on mood (Chrea et al., 2009).

\section{Aromatherapy}

Aromatherapy is the thousands years of the traditional herbal treatment method of countries like Egypt and India (Cooke and Ernst, 2000). However, modern science has also accepted it. Ballard, O'Brien, Reichelt and Perry (2002) have studied the effect of a pleasant fragrance presentation on dementia patients in a study. After a 4-week follow-up period with 71 participants, they reported that balmy smell was an effective and reliable way to treat dementia and improved quality of life. In another study, sedative effect of lavender smell on rats was determined (Buchbauer, Jirovetz, Jager, Dietrich and Plank, 1991). There is also a great deal of evidence that aromatherapy affects mood and behavior in a positive way (Diego et al., 1998; Field et al., 2005; Herz, 2009; Rho, Han, Kim and Lee, 2006).

\section{Conclusion and Recommendation}

While accepting that odor is a complex variable, its effect on behavior cannot be ignored. Odor can be used as a facilitating factor in many cognitive performance tasks, and it can be important in terms of human emotions. In addition, both the aromatherapy and effect of odors on mood are useful for many illnesses.

In the field of psychology, odor relevant studies are less as compared to other emotional studies. According to findings in the literature, odors affect human behaviors in a relatively more implicit way. This relativity indicates that odors may have more effect on behavior. In experiments aiming the effects of different smells the use of brain imaging will be very beneficial to identify the odor-psychology relation.

There may be some reasons for the lack of psychology studies on odor variable. First, it is very difficult to use odor in an experiment. If odor is sprayed it cannot be determined whether the participant has perceived this odor except perceptual measurements. The downside is that perceptual measurements or self-reports are not always accurate. There is no such worry in aromatherapy studies. The main aim of this study is to increase the quality of life, well-being and happiness of the participants. Furthermore, the odor may be used to increase the mood of participant in many psychological experiments. Mood and aromatherapy studies resulted in better outcomes than the 
cognitive performance tasks and the odor application without knowledge of participants.

\section{Giriş}

Kapsadığı alanın genişliğinden dolayı psikoloji bilimi pek çok farklı bilim dalıyla, araştırma alanıyla birlikte çalışmayı gerektirmektedir. Bunların yanında psikoloji araştırmaları içerisinde görsel, işitsel ve hatta dokunmayla ilgili pek çok uyarıcı kullanılmakta ve incelenmektedir (ör. Bottari ve ark., 2014; Eramudugolla, Irvine, Mcanally, Martin ve Mattingley, 2005; Fenn, Shintel ve Bond, 2011; Hood, Willen ve Driver, 1998; Velasco ve ark., 2016). Bunlar çeşitli görselleri gösterme, bazı görevleri el becerileriyle tamamlayabilme, bazı seslerin çeşitli görevlere etkisini inceleme gibi çok farklı şekillerde ortaya çıkmaktadır. Bütün bu uyaranlar düşünüldüğünde belki de en az araştırılan uyarıcı çeşitlerinden biri kokusal uyaranlardır.

Koku ve psikoloji arasındaki ilişkiyi inceleyen çalışmalar diğer duyularımızla ilgili yapılan çalışmalara kıyasla daha az olsa da yok değildir (ör. Rasch, Buchel, Gais ve Born, 2007; Rihm, Diekelmann, Born ve Rasch, 2014; Ritter ve ark., 2012). Yine de bu alan görece çok gelişmemiş bir alandır ve ilerlemeye de bir hayli müsaittir. Genel anlamda kokuların bellek, dikkat ve duygudurum üzerindeki etkileri ve aromaterapi en çok çalışılan konular arasinda yer alır (Buckle, 2001; Chu ve Downes, 2002; Cooke ve Ernst, 2000; Ilmberger ve ark., 2001; Lehrner, Eckersberger, Walla, Pötsch ve Deecke, 2000; Lehrner, Marwinski, Lehr, Johren ve Deecke, 2005; Ludvigson ve Rottman, 1989; Millot, Brand ve Morand, 2002; Rubin, Groth ve Goldsmith, 1984).

Bu çalışmadaki ilk amaç psikoloji alanında aromatik (hoş kokan) kokular ile yapılan bu araştırmaların özetlenmesi ve bu alanda yapılacak olan gelecek çalışmalara 1şık tutmaktır. Bu bağlamda aromatik kokuların duyguduruma, iyi oluşa ve bilişsel performansa etkileri tartışılacaktır. Diğer bir amaç ise koku çalışmalarındaki zorluğun sebeplerini açıklamak ve yeni çalışmalarda izlenebilecek yöntemleri irdelemektir.

\section{Koku ve Bellek}

Şüphesiz ki kokuların etkilerinin gözlemlendiği önemli değişkenlerden biri bellektir. Bilgileri bellekten geri getirme aracı olarak kullanılabilmesi kokunun en önemli özelliği sayılabilir. Özellikle otobiyografik bellekte hatırlatıcı ipuçları olarak kokular kullanılabilir (Chu ve Downes, 2000, 2002; Rubin, 
Groth ve Goldsmith, 1984). Chu ve Downes (2000) yapmış oldukları bir çalışmada 6-10 yaşlarındaki anıların kokular aracılığıyla otobiyografik bellekten başarılı bir şekilde geri getirildiğini göstermiştir. Rubin, Groth ve Goldsmith (1984) ise kokunun görsel uyaranlara göre daha iyi bir geri getirme aracı olmadığını belirtmesine rağmen duygusal ve hoşnut edici bilgileri geri getirmede daha iyi bir uyarıcı olabileceğini belirtmiştir. Daniels ve Vermetten'in (2016) derleme çalışmasında da koku ve bellek arasındaki ilişkinin daha çok duygusal bağlamda ele alınması gerektiği vurgulanmaktadır. Alanyazın bilgileri 1şığında düşünüldüğünde kokuların diğer duyularımızdan daha iyi bir geri getirme aracı olarak kullanılabileceği söylenemez ancak yine de spesifik anıları ve bilgileri geri getirmede önemli bir uyarıcı olduğu söylenebilir.

Eski anıları geri getirmenin yanında yeni öğrenilen bilgiler de koku ile birlikte koşullandırılabilir (Ritter, Strick, Bos, Van Baaren ve Dijksterhuis, 2012). Ritter ve arkadaşları tarafından yürütülen bu çalışmada öğrenilmesi gereken bilgiler katılımcılara koku ile birlikte sunulmuştur. Aynı günün gecesinde, uyku esnasında aynı kokunun tekrar sunulması sonucunda ertesi gün gerçekleşen yaratıcılık performansı artmıştır. Bu da kokunun pasif olarak dahi bireyde hatırlatıcı bir etkisi olduğunu göstermektedir ve bilişsel performans görevlerinde de kokunun etkisini ortaya koymaktadır. Akben'in (2015) tez çalışmasında ise kokunun beyin firtınası performansı üzerindeki etkisi bellekten geri getirme aracılığıyla incelenmiştir. Yaratıcılık görevinde kolaylaştırıcı bir etken olan bilişsel uyarıcı kelimeler katılımcılara görevden önce sunulurken ortama mandalina kokusu sıkılmıştır. Yine yaratıcılık görevi esnasında aynı kokunun tekrar verilmesi katılımcılarda bu kelimeleri hatırlatıcı bir etki göstermiştir. Bu kelimeler yardımıyla da üretilen düşünce sayısı artırmıştır. $\mathrm{Bu}$ iki çalışma da beyin firtınası görevleri esnasında kokunun bellekten geri getirmedeki etkisini ortaya koymaktadır. Kokunun yaratıcılık görevlerindeki etkisi bu çalışmalarda açık bir şekilde görülmektedir. Ayrıca yaratıcılık birçok psikolojik değişkenle ve kişilikle ilişkili bir değişkendir (Coşkun ve Şenyurt, 2015). Bu açıdan kokunun yaratıcılığa etkisi oldukça önemlidir.

Kokular bağlama bağlı bellek açısından da geri getirmede önemli bir uyarıcıdır (Chu ve Downes, 2002; Ehrlichman ve Halpern, 1988; Herz, 1997, 1998). Bu yaklaşıma göre bilgiler bellekte depolanırken beraberinde çevresel uyarıcılar da depolanır ve bilgiler geri getirilirken bu çevresel uyarıcılar ipucu olarak kullanılabilir (Smith ve Vela, 2001). Başka bir ifadeyle eğer bilgileri 
depolarken aynı ya da benzer bir ortama yeniden girersek bilgileri geri getirmemiz daha kolay olur (Godden ve Baddeley, 1975). Dahası aynı duygudurumda hissetmek bile bu kolaylaştırıcı etkiyi sağlar (Eich ve Metcalfe, 1989). Koku duyumuz da bağlama bağlı bellek için önemli bir ipucu teşkil eder (Chu ve Downes, 2002; Ehrlichman ve Halpern, 1988; Herz, 1997, 1998; Herz, Schankler ve Beland, 2004; Ritter ve ark., 2012; Wiemers, Sauvage ve Wolf, 2014). Ehrlichman ve Halpern (1988) çalışmalarında katılımcılara hoşnut edici ve kötü kokular sunmuşlardır. Koku daha güzel oldukça katılımcıların hatırladıkları anılar da daha güzel olmuştur. Herz, Schankler ve Beland (2004) ise katılımcılara pozitif ve negatif kokular dâhil olmak üzere çeşitli kokular sunmuştur. Daha sonra verilen yap-boz görevinde aynı kokuyu alan katılımc1lar problemi çözmek için daha az zaman harcamışlardır.

Bu deneyimler günlük yaşamımızda da sıkça rastlanılan bir durumdur. Birçoğumuz bir koku duyduğumuzda bununla bağlantılı anıları hatırlayabiliriz ya da bir parfüm kokusu duymak o parfümü kullanan kişileri bize çağrıştırabilir. Alanyazındaki çalışmalar da bu deneyimlerin laboratuvar ortamında incelenme çabası olarak düşünülebilir.

\section{Koku ve Dikkat}

Koku ve dikkat arasındaki ilişki tam anlamıyla tanımlanmış bir ilişki değildir. Bu bağlamda yapılan araştırma sayısı az olmakla birlikte etkileyici sonuçlar da alanyazında mevcuttur. Ilmberger ve arkadaşları (2001) araştırmalarında kokuların dikkat ve tepki sürelerinde bir etkisinin olmadığını bulmuştur. Buna rağmen koku alan katılımcıların algısal ölçümleri ile sonuçları arasındaki ilişki yüksek çıkmıştır. Yani koku alan katılımcılar daha iyi bir performans göstermemesine rağmen kendilerini daha başarılı algılamıştır. $\mathrm{Bu}$ araştırmanın tartışmasında ise bu durum kokunun dikkat ile ilişkisinin daha çok psikolojik olmasıyla açıklanmıştır.

Millot, Brand ve Morand (2002) yapmış oldukları araştırmanın sonucunda, pozitif ve negatif koku alan katılımcıların tepki sürelerinde düşüş gözlemlemişlerdir. Bu da kokunun hoşnut olup olmamasından bağımsız bir şekilde karar almayı hızlandırdığını ortaya koymaktadır. Michael, Jacquot, Millot ve Brand'in (2003) çalışmasında ise kokuların kısa süreli görsel dikkat üzerindeki etkisi incelenmiştir ve kokunun karakteristik özelliklerine göre dikkatin değişim gösterdiği bulunmuştur.

Diğer çalışmalardan farklı olarak kokunun çağrışımsal olarak dikkat 
üzerindeki etkisini inceleyen Seo, Roidl, Müller ve Negoias (2010) hazırladıkları deneyde göz tarama cihazı kullanmışlardır. Ekranda gösterilen üç çeşit gıda maddesinden biri ile eşleşen bir koku ortama sunulduğu zaman katılımcıların eşleşen gıdanın resmine daha çok baktıkları bulunmuştur.

Özet olarak koku ve dikkat arasındaki ilişki apaçık bir şekilde belirtilecek cinsten değildir. Tepki süresi bağlamında kokuların genel olarak katılımcıları hızlandırdığı söylenebilirken kısa süreli dikkat bağlamında kokunun karakteristik özelliğinden söz edilebilir. Aynı şekilde kokunun çeşitli uyaranlarla eşleşmesi de dolaylı yoldan dikkat süreçlerine etkide bulunmaktadır. Koku ve dikkat arasındaki bu ilişki, bağlam ve yöntem çerçevesinde değişen bir ilişkidir. Bunların birbirinden çok da bağımsız değişkenler olmadıkları söyleyenebilir. Belki de üzerinde durulması gereken önemli bir konu da koku ve dikkat arasında beyin aktivasyonu açısından da bazı ortak noktalar bulunduğudur.

\section{Koku ve Beyin Aktivasyonu}

Diğer duyularımıza göre daha geri planda gibi gözükse de koku duyumuz birçok beyin aktivasyonuna sebep olmaktadır. Beynimizde olfaktör epitel içerisinde yaklaşık olarak altı milyon reseptör hücre bulunur. Dışarıdan aldığımız havanın \%10 kadarı bu merkeze ulaşabilir ve moleküller bu reseptör hücreler yardımıyla alınır. Olfaktör reseptör hücreler olarak adlandırılan bu hücreler diğer birçok nörondan farklı olmak üzere sürekli olarak yeniden üretilebilir. Bu hücreler olfaktör bulb denilen beyin bölgesine molekülleri gönderirler ve iletici hücreler aracılığıly koku amigdalaya ve limbik sisteme ulaştırılır. Amigdaladan sonra ise bu koku bilgisi çeşitli yollardan geçer ve en sonunda hipotalamusa ve orbitofrontal kortekse gönderilir (Carlson, 2010, s. 206). Yine de koku duyusunun diğer duyular gibi belirli merkezlerde işleniyor olduğunu söylemek zordur. Bu da dikkat süreçlerinin de kortekse yayıllyor olmasıyla paralel bir durumu ortaya çıkarmaktadır.

Beynimizin kokularla ilişkili bölümü diyebileceğimiz olfaktör korteks ile ilgili çok sayıda beyin görüntüleme çalışması yapılmıştır. Seubert, Freiherr, Djordjevic ve Lundström (2013) bu alanda yapılan kırk beş çalışmanın bir meta-analizini yapmışlardır. Ortaya çıkan sonuçlara göre kokuların etkilediği temel alanlar olarak amigdala ve orbitofrontal korteks bulunmuştur. Amigdala ile ilgili aktivasyon kokuların duygularla ilişkisini açıklarken orbitofrontal korteks ile ilgili aktivasyon ise bilişsel performans görevlerindeki kokunun etkisine bir açıklama niteliği taşıyabilir. Bu çalışma kokunun beynimizdeki aktivasyonunu açıklamak açısından oldukça değerli bir çalışmadır. 


\section{Koku ve Duygudurum}

Kokunun belki de günlük hayatımızda en etkili olduğu alanlardan biri duygudurumumuzdur. Kokunun duygudurum üzerindeki etkisi birçok açıdan ele alınabilir. Bağlama bağlı bellek kavramı içerisinde Dolcos, LaBar ve Cabeza (2005) bir çalışmada katılımcılara nötr ve duygusal yüklü resimler göstermişlerdir ve bir yıl aradan sonra aynı resimleri tekrar gösterirken katılımc1ların fMRI görüntülerini almışlardır. Duygusal yüklü resimler gösterilirken katılımcıların amigdalasında aktivasyonun daha çok olduğu bulunmuştur. Yukarıda belirtildiği üzere Ehrlichman ve Halpern'in (1988) çalışmasında da duygudurum ele alınmıştır. Hoş koku alan katılımcılar olayları daha olumlu hatırlarken, hoș olmayan koku alanlar ise daha olumsuz anıları hatırlamıștır. Bu bulgular da özellikle amigdala ile koku arasındaki ilişkiyi vurgulamaktadır ve bilindiği üzere amigdala da duygu yüklü anılarla doğrudan ilişkilidir (Wang, LaBar ve McCarthy, 2006).

Bunların yanında kokuların doğrudan duygudurumu etkilediğine dair de pek çok bulgu vardır. Lehrner ve arkadaşlarının (2005) çalışmasında portakal ve lavanta kokuları duygudurumu pozitif hâle getirirken kaygıyı da azaltmaktadır. Diego ve arkadaşlarının (1998) çalışmasında da aynı şekilde lavantanın rahatlatıcı etkisi rapor edilmiştir. Lehrner ve arkadaşlarının (2000) bir çalışmasında ise portakal kokusunun hastalar üzerinde kaygıyı azaltıcı bir etkisi olduğu ve duygudurumu pozitif hâle getirdiği bulunmuştur. Lehrner ve arkadaşları (2005) yapmış oldukları bir diğer çalışmada ise portakal ve lavanta kokularının duygudurumu artırdığını ve kaygıyı azalttığını rapor etmiştir. Diğer bazı çalışmalarda da lavantanın rahatlatıcı etkisi tespit edilmiştir (Diego ve ark., 1998; Field ve ark., 2005; Ludvigson ve Rottman, 1989; Moss ve ark., 2003). Hatta fareler üzerinde yapılan bir çalışmada lavanta kokusunun farelerde yatıştırıcı bir etkisinin olduğu ortaya konmuştur (Buchbauer, Jirovetz, Jager, Dietrich ve Plank, 1991). Bunlar dışında da pek çok farklı duygudurum (rahat, sakin, coşkun, üzgün...) üzerinde farklı kokuların (vanilya, lavanta, portakal...) etkileri olduğu bilinmektedir (Warrenburg, 2005).

Her kokunun ise insanlarda farklı duygudurumlara yol açtığı bir gerçektir. Müge rahatlatıcı olabilirken nane kokusu daha uyarıcı bir etki gösterebilmektedir (Warm, Dember ve Parasuraman, 1991). Biberiye kokusu uyarıcı bir etkiye neden olabilir (Diego ve ark., 1998). Duygudurumu etkilerken farklı kokular beyindeki farklı alanları da etkileyebilir (Lorig ve Schwartz, 1988). $\mathrm{Bu}$ bağlamda kokuların duygudurum üzerindeki etkilerinin ölçülebilmesi 
amaciyla Cenevre Duygu ve Koku Ölçeği de geliştirilmiştir (Chrea ve ark., 2009). Porcherot ve ark. (2010) bu ölçeği de kullanarak çalışmalarında katılımcıların farklı kokuları farklı değerlendirdiklerini rapor etmiştir.

Kokuların duygudurum üzerindeki etkileri üzerine yapılmış bu kadar fazla araştırma varken şüphesiz ki bu alanın uygulamasının olması da kaçınılmazdır. Bu bağlamda aşağıda da belirtildiği üzere aromaterapi denilince duygudurumu pozitif yönde etkilemek amacıyla kokuların kullanımı akla gelmektedir.

\section{Aromaterapi}

Kokuların duygudurum üzerindeki etkileri literatürde yaygın olarak ça1ış1lan bir alan olmakla birlikte yeni bilinen bir konu değildir. Kokular birçok eski medeniyetten günümüze bir terapi yöntemi olarak kullanılagelmiştir. Aromaterapi, Mısır ve Hindistan gibi ülkelerde binlerce yıllık geleneğe dayalı bir bitkisel tedavi yöntemidir (Cooke ve Ernst, 2000). Bu yöntemde doğal otlardan, çiçeklerden ve bitkilerden elde edilen aromatik esanslar kullanılır (Perry ve Perry, 2006). Her ne kadar eski bir gelenek de olsa aromaterapi modern bilimde kendine yer bulmuştur. Bu bağlamda yakın zaman içerisinde ABD'de hemşireler de mesleklerinde aromaterapiyi kullanır hâle gelmişlerdir (Buckle, 2001; Stevensen, 1994). Aromaterapi çalışmaları özellikle kokuların duygudurum üzerindeki etkilerinden yola çıkarak hastaların iyi oluşunu artırma amacıyla kullanılmaktadır. Bu amaç doğrultusunda aromaterapinin duygudurumu ve davranışı pozitif yönde etkilediğine dair de pek çok çalışma bulunmaktadır (Diego ve ark., 1998; Field ve ark., 2005; Herz, 2009; Moss ve ark., 2003; Moss, Hewitt, Moss ve Wesnes, 2008; Rho, Han, Kim ve Lee, 2006).

Aromaterapinin günümüzde bir tedavi yöntemi olarak kullanıldığı hastalıklardan biri demanstır. Ballard ve arkadaşları (2002) yaptıkları bir çalışmada güzel koku sunumunun demans hastaları üzerindeki etkisini incelemiştir. Dört haftalık süreçten sonra melisa kokusunun demans tedavisinde etkili ve güvenilir bir yol olduğunu ve yaşam kalitesini artırdığını rapor etmişlerdir. Smallwood, Brown, Coulter, Irvine ve Copland (2001) da demans hastalar1 ile yaptığı bir çalışmada aromaterapinin özellikle masaj uygulamaları ile birlikte hastalar üzerinde semptomları azaltıcı bir sonuç verdiğini göstermiştir. Demans hastaları üzerinde yapılan çalışmalar genellikle bu hastalardaki stres ve gerilimin azaldığını da rapor etmektedir (Ballard ve ark., 2002; Holmes ve ark., 2002; Smallwood ve ark., 2001). Snow, Hovanec ve Brandt (2004) ise 
bu bulgulara karşı olarak yaptıkları çalışmayla demans hastaları üzerindeki bu etkinin, bu hastaların koku alma yetilerinde yaşanan büyük hasarlardan dolayı mümkün olamayacağını önermiştir.

Parkinson hastaları ile yapılan çalışmalarda da aromaterapinin hastalara iyi geldiği rapor edilmiştir (Ferry, Johnson ve Wallis, 2002). Yine benzer bir bulgu şizofreni hastalarında da görülmüştür (Hicks, 1998). Burada belirtilmesi gereken önemli bir nokta aromaterapinin tüm bu etkileri hastalığın giderilmesi yönünde değildir. Daha çok hastalığın semptomlarını azaltma yönünde bir etki söz konusudur. Sözü edilen çalışmalarda aromaterapinin en etkili olduğu semptomlardan birisi de rahat bir uyku eksikliğidir. Bununla ilişkili olarak doğrudan uyku bozukluklarında da aromaterapinin önemli etkileri söz konusudur. Özellikle masaj uygulamaları ile birlikte lavanta ve benzeri etkilerde rahatlatıcı kokuların uyku bozukluğu olan hastalarda uyku kalitesini artırdığı bilinmektedir (Cannard, 1996; Hardy, Kirk-Smith ve Stretch, 1995).

Aromaterapinin kaygı bozukluğuna ve depresyona sahip hastalarda da etkili olduğu bilinmektedir. Aromatik koku alan katılımcıların kaygı düzeylerinde düşüş gözlemlenmektedir (Dunn, Sleep ve Collett, 1995; Edge, 2003; Lehrner ve ark., 2000). Bu sonuçlarla tutarlı bir şekilde aromaterapinin depresyon hastaları üzerinde de semptomları azaltıcı etkiler gösterdiği bulunmuştur (Komori, Fujiwara, Tanida, Nomura ve Yokoyama, 1995). Aromaterapinin psikiyatrik hastalıklardaki etkisi genel anlamda düşünüldügünde sakinleştirme ve yatıştırma üzerine etki göze çarpmaktadır (Buchbauer ve ark., 1991; Buchbauer, Jirovetz, Jager, Plank ve Dietrich, 1993).

\section{Sonuç ve Öneriler}

Koku duyumuzu tek bir boyutta düşünmek mümkün değildir. Kokular farklılaştıkça insanlarda farklı etkilere neden olabilmektedir. Bu durum bazen duygudurum üzerinde bazen de bilişsel performanslar üzerinde geçerli olabilir. Bu yüzden koku değişkeni için net bir çerçeve çizmek mümkün değildir. Öte yandan nasıl ki görsel ve işitsel uyaran değişkenleri için değişkenin niteliğine göre davranışların değiştiği söylenebilirse, koku değişkeni için de aynı değerlendirmeyi yapabiliriz. Yani daha önce de söz edildiği üzere bazı kokular daha uyarıcı olabilirken bazı kokular daha yatıştıııcı etkiye sahip olabilmektedir (Diego ve ark., 1998; Field ve ark., 2005; Ludvigson ve Rottman, 1989; Moss ve ark., 2003) 
Kokunun karmaşık bir değişken olduğunu kabul etmekle birlikte davranış üzerindeki etkisi de görmezden gelinemez. Birçok bilişsel performans görevinde kokular kolaylaştırıcı bir etken olarak kullanılabilir. Özellikle bellekten geri getirme aracı olarak kokuların önemli bir ipucu olarak kullanılması mümkündür (Chu ve Downes, 2000; Ehrlichman ve Halpern, 1988; Rubin, Groth ve Goldsmith, 1984). Bunun yanında yaratıcılık görevlerinde de daha esnek düşünmeye katkı sağlaması açısından koku önemli bir uyarandır (Akben, 2015; Ritter ve ark., 2012). Dikkat ile aromatik kokular arasındaki bağlantı hâlen net olarak tanımlanamasa da dikkat görevlerinde de kokuların kolaylaştırıcı bir etkiye sahip olduğu gerçektir. (Ilmberger ve ark., 2001; Millot ve Brand, 2001; Seo ve ark., 2010) Bu ve benzeri etkiler düşünüldüğünde, gündelik yaşantıda kokuların bilişsel süreçlere sağlayacağı katkılar bağlamında birçok yeni uygulama geliştirilebilir. Özellikle eğitim alanında bilişsel performansı artırmak ve öğrenmeyi güçlendirmek açısından kokuların kullanılmasının faydalı olacağı öngörülmektedir. Aynı zamanda daha uyarıcı nitelikte aromatik kokuların kullanımı da öğrencilerin motivasyonlarını artıracaktir.

Duygudurum açısından da aynı şekilde kokular insan hayatında önemli bir yer teşkil edebilir. Farklı kokuların farklı duygudurumlara sebebiyet verdiği bilinmektedir (Diego ve ark., 1998; Warm, Dember ve Parasuraman 1991). Bu bilgiler de hemen herkesin gündelik hayatta kullanabileceği pratiklere dökülebilirken, bunların büyük organizasyonlara da katkı sağlaması mümkündür. Satış ve pazarlama alanında müşterilerin duygudurumlarını artırmak için aromatik koku kullanımının yaygınlaştırılması oldukça faydalı bir yöntem olacaktır. Bu yöntem hâlihazırda pek çok işletme tarafından da kullanılan ve araştırmalarca da desteklenmiş bir yöntemdir (Guéguen ve Petr, 2006; Mitchell, Kahn ve Knasko, 1995). Bununla birlikte çalışma ve ofis ortamlarında da aromatik koku kullanımının çalışma performansını artırması beklenmesi gereken bir sonuçtur (Lehrner ve ark., 2000).

Ayrıca duygudurum üzerindeki bu etkiler ve aromaterapi uygulamaları birçok hastalık için yararlı olabilir. Literatür incelendiğinde aromaterapinin demans, parkinson, şizofreni, uyku bozuklukları, kaygı bozukluğu gibi birçok psikiyatrik hastalıkta etkili bir tedavi yöntemi olarak kullanıldığı görülmektedir. (Ballard ve ark., 2002; Cannard, 1996; Dunn, Sleep ve Collett, 1995; Edge, 2003; Ferry, Johnson ve Wallis, 2002; Hicks, 1998; Holmes ve ark., 2002; Lehrner ve ark., 2000; Smallwood ve ark., 2001). Aromaterapinin bu 
hastalıklar üzerindeki etkileri hastalığın semptomlarını yatıştırıcı nitelikte tezahür etmektedir (Buchbauer ve ark., 1991, 1993). Doğal olarak aromatik kokuların bu yatıştırıcı etkileri depresyon hastalarında da görülmekte ve kaygı düzeyini düşürmektedir (Dunn, Sleep ve Collett, 1995; Komori ve ark., 1995; Lehrner ve ark., 2000, 2005). Sonuç olarak aromatik kokuların duygudurumdaki olumlu etkilerinin sadece hastalıklarla sınırlı kalamayacağını söylemek gerekir. Günlük yaşantımızda dahi aromatik kokular koklamamız iyi oluşumuza katkı sağlayacaktır (Duan ve ark., 2007; Promsomboon, Promsomboon, Kornpetpanee ve Pothisonothai, 2014).

Psikoloji alanındaki koku çalışmalarının diğer duyulara göre daha az çalışılmış olması bu alandaki boşluğa da işaret etmektedir. Özetlenen birçok çalışmanın geliştirilmesi ve kokunun davranışlarımız üzerindeki etkisinin daha iyi araştırılmasına ihtiyaç olduğu söylenebilir. Alanyazındaki bulgular değerlendirildiğinde aromaterapi uygulamaları dışında kokuların nispeten daha örtük bir şekilde davranışlarımızı etkilediği görülmektedir. Bu durum da aslında beraberinde kokuların davranış üzerinde daha fazla etkisinin olabileceğini düşündürmektedir. Özellikle gelecek çalışmalarda bilişsel performans görevlerinde kokuların etkisine bakılırken, katılımcıların kokudan haberdar olmalarının nasıl bir sonuç getirdiği incelenmelidir. Beyin görüntüleme çalışmaları açısından da koku ve psikoloji bağlantısı oldukça zayıftır. Birçok farklı koku türünün duygudurumumuza ve davranışlarımıza farklı etkilerinin olduğu bilinmektedir. Bu çerçeve dahilinde farklı kokuların etkileri deneysel bir şekilde incelenirken beynin görüntülenmesi koku ve psikoloji bağlantısını açıklamakta büyük bir fayda sağlayacaktır. Birbirine algısal olarak oldukça benzerlik taşıyan kokuların bile çok farklı nörofizyolojik tepkilere sebebiyet verdiği bilinmektedir (Lorig ve Schwartz, 1988). Bundan dolayı algısal ölçümlerin sınırlılılığından kurtularak kokuların karakteristik etkilerini beyin görüntüleme cihazları ile açıklamak oldukça önemlidir. Böylece hangi kokuların duyguduruma nasıl etkiler verdiğini özbildirim yöntemiyle ölçmenin sınırl1lıkları da aşılmış olacaktır. Özellikle kokuların karakteristik özellikleri yarattıkları beyin dalgaları aracılığıyla açıklanmalıdır.

Koku değişkeninin psikoloji bağlamında daha az çalış1lıyor olmasının bazı sebepleri olabilir. Öncelikle belirtmek gerekir ki bir deneyde koku kullanmak gerçekten zordur. Bu zorluğun en önemli sebebi ise kokunun ortama ya da katılımcılara verilmesi sürecinin kendisidir. Koku ortama sıkıldığında 
katılımcının bu kokuyu duyup duymadığını, algısal ölçümler hâricinde öğrenmek mümkün değildir. İşin olumsuz bir yanı ise algısal ölçümler katılımcıların deney sonrası cevaplarını içerdiği için her zaman doğruyu göstermemektedir. Örneğin Ritter ve arkadaşları (2012) tarafından ve Akben (2015) tarafından yapılan her iki çalışmada da katılımcıların kokuyu aldığına dâir algısal ölçümler dışında somut bir kanıt bulunmamaktadır. Bu zorluktan kurtulmak için yapılabilecek yöntemlerden biri kokuyu katılımcıya mümkün olduğu kadar yakın tutmaktır. Bu defa da araştırmanın ne için yapıldığının anlaşılması bir tehlike arz edebilir.

Aromaterapi çalışmalarında ise böyle bir kaygıya yer yoktur. Temel gaye zaten katılımcıların hayat kalitesini, iyi oluşunu ve mutluluk düzeylerini artırmaktır. Aromaterapi dışında yine birçok psikolojik deneyde duygudurumu artırmak amacıyla da katılımcılara koku koklatılabilir. Bilişsel performans görevlerinden ve kokunun katılımcıların haberi olmaksızın uygulanmasından ziyade duygudurum ve aromaterapi çalışmaları görece daha uygulanabilir sonuçlar vermektedir. Bu nedenle bu alanda yapılacak çalışmalara görece daha çok gereksinim olduğunu söylemek mümkündür.

\section{Kaynakça}

Akben, C. (2015). Koku ve bilişsel uyarımın beyin firtınasında yaratıcılığa etkisi. Yayınlanmamış yüksek lisans tezi, Abant İzzet Baysal Üniversitesi Sosyal Bilimler Enstitüsü.

Ballard, C. G., O'Brien, J. T., Reichelt, K. ve Perry, E. K. (2002). Aromatherapy as a safe and effective treatment for the management of agitation in severe dementia: The results of a double-blind, placebocontrolled trial with Melissa. The Journal of Clinical Psychiatry, 63(7), 553-558.

Bottari, D., Heimler, B., Caclin, A., Dalmolin, A., Giard, M. ve Pavani, F. (2014). Visual change detection recruits auditory cortices in early deafness. NeuroImage, 94, 172-184.

Doi: 10.1016/j.neuroimage.2014.02.031

Buchbauer, G., Jirovetz, L., Jager, W., Dietrich, H. ve Plank, C. (1991). Aromatherapy: Evidence for sedative effects of the essential oil of lavender after inhalation. Zeitschrift Fur Naturforschung C, 46(11-12), 1067-1072.

Buchbauer, G., Jirovetz, L., Jager, W., Plank, C. ve Dietrich, H. (1993). 
Fragrance compounds and essential oils with sedative effects upon inhalation. Journal of Pharmaceutical Sciences, 82(6), 660-664.

Buckle, J. (2001). The role of aromatherapy in nursing care. The Nursing Clinics of North America, 36(1), 57-72.

Cannard, G. (1996). The effect of aromatherapy in promoting relaxation and stress reduction in a general hospital. Complementary Therapies in Nursing \& Midwifery, 2(2), 38-40.

Carlson, N. R. (2010). Fizyolojik psikoloji: davranışın nörolojik temelleri. (M. Şahin, Çev.) Ankara: Nobel Akademik Yayıncılık.

Chrea, C., Grandjean, D., Delplanque, S., Cayeux, I., Le Calvé, B., Aymard, L., Velazco, M. I., Sander, D. ve Scherer, K. R. (2009). Mapping the semantic space for the subjective experience of emotional responses to odors. Chemical Senses, 34(1), 49-62.

Doi: $10.1093 /$ chemse/bjn052

Chu, S. ve Downes, J. J. (2000). Long live Proust: The odour-cued autobiographical memory bump. Cognition, 75(2000), B41-B50.

Doi: 10.1016/S0010-0277(00)00065-2

Chu, S. ve Downes, J. J. (2002). Proust nose best: Odors are better cues of autobiographical memory. Memory \& Cognition, 30(4), 511-518.

Doi: 10.3758/BF03194952

Cooke, B. ve Ernst, E. (2000). Aromatherapy: A systematic review. British Journal of General Practice, 50, 493-496.

Coşkun, H. ve Şenyurt, A. Y. (2015). Kişilik ve yaratıcılık ilişkisini inceleyen çalışmaların kullanılan ölçme araçlarına göre değerlendirilmesi. Kalem Uluslararası Eğitim ve Insan Bilimleri Dergisi, 5(2), 35-65.

Daniels, J. K. ve Vermetten, E. (2016). Odor-induced recall of emotional memories in PTSD-Review and new paradigm for research. Experimental Neurology, 284, 168-180.

https://doi.org/10.1016/j.expneurol.2016.08.001

Diego, M. A., Jones, N. A., Field, T., Hernandez-reif, M., Schanberg, S., Kuhn, C., Galamaga, M., McAdam, V. ve Galamaga, R. (1998). Aromatherapy positively affects mood, eeg patterns of alertness and math computations. International Journal of Neuroscience, 96(3-4), 
217-224.

Doi: $10.3109 / 00207459808986469$

Dolcos, F., LaBar, K. S. ve Cabeza, R. (2005). Remembering one year later: Role of the amygdala and the medial temporal lobe memory system in retrieving emotional memories. Proceedings of the National Academy of Sciences of the United States of America, 102(7), 2626-2631.

Doi: 10.1073/pnas.0409848102

Duan, X., Tashiro, M., Wu, D., Yambe, T., Wang, Q., Sasaki, T., Kumagai, K., Luo, Y., Nitta, S. ve Itoh, M. (2007). Autonomic nervous function and localization of cerebral activity during lavender aromatic immersion. Technology and Health Care: Official Journal of the European Society for Engineering and Medicine, 15(2), 69-78.

Doi: 10.1142/9781860948800_0076

Dunn, C., Sleep, J. ve Collett, D. (1995). Sensing an improvement: An experimental study to evaluate the use of aromatherapy, massage and periods of rest in an intensive care unit. Journal of Advanced Nursing, 21(1), 34-40.

Edge, J. (2003). A pilot study addressing the effect of aromatherapy massage on mood, anxiety and relaxation in adult mental health. Complementary Therapies in Nursing \& Midwifery, 9(2), 90-97.

Doi: 10.1016/S1353-6117(02)00104-X

Ehrlichman, H. ve Halpern, J. N. (1988). Affect and memory: Effects of pleasant and unpleasant odors on retrieval of happy and unhappy memories. Journal of Personality and Social Psychology, 55(5), 769779.

Doi: $10.1037 / 0022-3514.55 .5 .769$

Eich, E. ve Metcalfe, J. (1989). Mood dependent memory for internal versus external events. Journal of Experimental Psychology: Learning, Memory, and Cognition, 15(3), 443-455.

Doi: 10.1037/0278-7393.15.3.443

Eramudugolla, R., Irvine, D. R. F., Mcanally, K. I., Martin, R. L. ve Mattingley, J. B. (2005). Directed attention eliminates " change deafness" in complex auditory scenes. Current Biology, 15, 1108-1113. Doi: 10.1016/j.cub.2005.05.051 
Fenn, K. M., Shintel, H. ve Bond, V. C. (2011). When less is heard than meets the ear: Change deafness in a telephone conversation. The Quarterly Journal of Experimental Psychology, 64(7), 1442-1456.

Doi: 10.1080/17470218.2011.570353

Ferry, P., Johnson, M. ve Wallis, P. (2002). Use of complementary therapies and non-prescribed medication in patients with Parkinson's disease. Postgraduate Medical Journal, 78(924), 612-614.

Doi: 10.1136/pmj.78.924.612

Field, T., Diego, M. A., Hernandez-Reif, M., Cisneros, W., Feijo, L., Vera, Y., Gil, K., Grina, D. ve Claire He, Q. (2005). Lavender fragrance cleansing gel effects on relaxation. International Journal of Neuroscience, 115(2), 207-222.

Doi: 10.1080/00207450590519175

Godden, D. R. ve Baddeley, A. D. (1975). Context-dependent memory in two natural environments: On land and underwater. British Journal of Psychology, 66(3), 325-331.

Doi: 10.1111/j.2044-8295.1975.tb01468.x

Guéguen, N. ve Petr, C. (2006). Odors and consumer behavior in a restaurant. International Journal of Hospitality Management, 25(2), 335-339.

Doi: 10.1016/j.ijhm.2005.04.007

Hardy, M., Kirk-Smith, M. D. ve Stretch, D. D. (1995). Replacement of drug treatment for insomnia by ambient odour. Lancet, 346(8976), 701. Doi: 10.1016/S0140-6736(95)92310-1

Herz, R. S. (1997). The effects of cue distinctiveness on odor-based contextdependent memory. Memory \& Cognition, 25(3), 375-380.

Doi: $10.3758 / \mathrm{BF} 03211293$

Herz, R. S. (1998). Are odors the best cues to memory? Annals of the New York Academy Sciences, 855, 670-674.

Doi: 10.1111/j.1749-6632.1998.tb10643.x

Herz, R. S. (2009). Aromatherapy facts and fictions: A scientific analysis of olfactory effects on mood, physiology and behavior. International Journal of Neuroscience, 119(2), 263-290.

Doi: 10.1080/00207450802333953 
Herz, R. S., Schankler, C. ve Beland, S. (2004). Olfaction, emotion and associative learning: Effects on motivated behavior. Motivation and Emotion, 28(4), 363-383.

Doi: $10.1007 / \mathrm{s} 11031-004-2389-\mathrm{x}$

Hicks, G. (1998). Aromatherapy as an adjunct to care in a mental health day hospital. Journal of Psychiatric and Mental Health Nursing, 5(4), 317.

Holmes, C., Hopkins, V., Hensford, C., MacLaughlin, V., Wilkinson, D. ve Rosenvinge, H. (2002). Lavender oil as a treatment for agitated behaviour in severe dementia: A placebo controlled study. International Journal of Geriatric Psychiatry, 17(4), 305-308.

Doi: $10.1002 /$ gps.593

Hood, B. M., Willen, J. D. ve Driver, J. (1998). Adult's eyes trigger shifts of visual attention in human infants. Psychological Science, 9(2), 131-134.

Ilmberger, J., Heuberger, E., Mahrhofer, C., Dessovic, H., Kowarik, D. ve Buchbauer, G. (2001). The influence of essential oils on human attention. I: Aletrness. Chemical Senses, 26, 239-245.

Doi: 10.1093/chemse/26.3.239

Komori, T., Fujiwara, R., Tanida, M., Nomura, J. ve Yokoyama, M. M. (1995). Effects of citrus fragrance on immune function and depressive states. Neuroimmunomodulation, 2(3), 174-180.

Lehrner, J., Eckersberger, C., Walla, P., Pötsch, G. ve Deecke, L. (2000). Ambient odor of orange in a dental office reduces anxiety and improves mood in female patients. Physiology and Behavior, 71(1-2), 83-86.

Doi: 10.1016/S0031-9384(00)00308-5

Lehrner, J., Marwinski, G., Lehr, S., Johren, P. ve Deecke, L. (2005). Ambient odors of orange and lavender reduce anxiety and improve mood in a dental office. Physiology and Behavior, 86(1-2), 92-95.

Doi: 10.1016/j.physbeh.2005.06.031

Lorig, T. S. ve Schwartz, G. E. (1988). Brain and odor: I. Alteration of human EEG by odor administration. Psychobiology, 16(3), 281-284.

Ludvigson, H. W. ve Rottman, T. R. (1989). Effects of ambient odors of lavender and cloves on cognition, memory, affect and mood. Chemical Senses, 14(4), 525-536. 
Michael, G. A., Jacquot, L., Millot, J. L. ve Brand, G. (2003). Ambient odors modulate visual attentional capture. Neuroscience Letters, 352(3), 221225.

Doi: 10.1016/j.neulet.2003.08.068

Millot, J. L. ve Brand, G. (2001). Effects of pleasant and unpleasant ambient odors on human voice pitch. Neuroscience Letters, 297(1), 61-63.

Doi: 10.1016/S0304-3940(00)01668-2

Millot, J. L., Brand, G. ve Morand, N. (2002). Effects of ambient odors on reaction time in humans. Neuroscience Letters, 322(2), 79-82.

Doi: 10.1016/S0304-3940(02)00092-7

Mitchell, D. J., Kahn, B. E. ve Knasko, S. C. (1995). There's something in the air: Effects of congruent or incongruent ambient odor on consumer decision making. Journal of Consumer Research, 22(2), 229-238.

Doi: $10.1086 / 209447$

Moss, M., Cook, J., Wesnes, K. ve Duckett, P. (2003). Aromas of rosemary and lavender essential oils differentially affect cognition and mood in healthy adults. International Journal of Neuroscience, 113(1), 15-38.

Doi: 10.1080/00207450390161903

Moss, M., Hewitt, S., Moss, L. ve Wesnes, K. (2008). Modulation of cognitive performance and mood by aromas of peppermint and ylang-ylang. The International Journal of Neuroscience, 118(1), 59-77.

Doi: 10.1080/00207450601042094

Perry, N. ve Perry, E. (2006). Aromatherapy in the management of psychiatric disorders. CNS Drugs, 20(4), 257-280.

Doi: 10.2165/00023210-200620040-00001

Porcherot, C., Delplanque, S., Raviot-Derrien, S., Calvé, B. L., Chrea, C., Gaudreau, N. ve Cayeux, I. (2010). How do you feel when you smell this? Optimization of a verbal measurement of odor-elicited emotions. Food Quality and Preference, 21(8), 938-947.

Doi: 10.1016/j.foodqual.2010.03.012

Promsomboon, S., Promsomboon, P., Kornpetpanee, S. ve Pothisonothai, M. (2014). Selection of odor from aromatic flowers for relaxing emotion. Acta Horticulturae, 1023, 29-34,

Doi: 10.17660/ActaHortic.2014.1023.2 
Rasch, B., Buchel, C., Gais, S. ve Born, J. (2007). Odor cues during slowwave prompt declarative memory consolidation. Science, 315, 14261429.

Doi: $10.1126 /$ science. 1138581

Rho, K.-H., Han, S.-H., Kim, K.-S. ve Lee, M. S. (2006). Effects of aromatherapy massage on anxiety and self-esteem in Korean elderly women: A pilot study. The International Journal of Neuroscience, 116(12), 1447-1455.

Doi: $10.1080 / 00207450500514268$

Rihm, J. S., Diekelmann, S., Born, J. ve Rasch, B. (2014). Reactivating memories during sleep by odors: Odor specificity and associated changes in sleep oscillations. Journal of Cognitive Neuroscience, 26(8), 1806-1818.

Doi:10.1162/jocn_a_00579

Ritter, S. M., Strick, M., Bos, M. W., Van Baaren, R. B. ve Dijksterhuis, A. (2012). Good morning creativity: Task reactivation during sleep enhances beneficial effect of sleep on creative performance. Journal of Sleep Research, 21(6), 643-647.

Doi: 10.1111/j.1365-2869.2012.01006.x

Rubin, D. C., Groth, E. ve Goldsmith, D. J. (1984). Olfactory cuing of autobiographical memory. The American Journal of Psychology, 97(4), 493-507.

Doi: $10.2307 / 1422158$

Seo, H. S., Roidl, E., Müller, F. ve Negoias, S. (2010). Odors enhance visual attention to congruent objects. Appetite, 54(3), 544-549.

Doi: 10.1016/j.appet.2010.02.011

Seubert, J., Freiherr, J., Djordjevic, J. ve Lundström, J. N. (2013). Statistical localization of human olfactory cortex. NeuroImage, 66, 333-342.

Doi: 10.1016/j.neuroimage.2012.10.030

Smallwood, J., Brown, R., Coulter, F., Irvine, E. ve Copland, C. (2001). Aromatherapy and behaviour disturbances in dementia: A randomized controlled trial. International Journal of Geriatric Psychiatry, 16(10), 1010-1013.

Smith, S. M. ve Vela, E. (2001). Environmental context-dependent memory. 
Psychonomic Bulletin \& Review, 8(2), 203-220.

Doi: 10.3758/BF03196157

Snow, L. A., Hovanec, L. ve Brandt, J. (2004). A controlled trial of aromatherapy for agitation in nursing home patients with dementia. Journal of Alternative \& Complementary Medicine, 10(3), 431-437.

Stevensen, C. (1994). The psychophysiological effects of aromatherapy massage following cardiac surgery. Complementary Therapies in Medicine, 2(1), 27-35.

Doi: 10.1016/0965-2299(94)90156-2

Velasco, C., Salgado-Montejo, A., Elliot, A. J., Woods, A. T., Alvarado, J. ve Spence, C. (2016). The shapes associated with approach / avoidance words. Motivation and Emotion, 40(5), 689-702.

Doi: 10.1007/s11031-016-9559-5

Wang, L., LaBar, K. S. ve McCarthy, G. (2006). Mood alters amygdala activation to sad distractors during an attentional task. Biological Psychiatry, 60(10), 1139-1146.

Doi: 10.1016/j.biopsych.2006.01.021

Warm, J. S., Dember, W. N. ve Parasuraman, R. (1991). Effects of olfactory stimulation on performance and stress in a visual sustained attention task. Journal of Society Cosmetic Chemists, 42(3), 199-210.

Warrenburg, S. (2005). Effects of fragrance on emotions: Moods and physiology. Chemical Senses, 30(1), 248-249.

Doi: 10.1093/chemse/bjh208

Wiemers, U. S., Sauvage, M. M. ve Wolf, O. T. (2014). Odors as effective retrieval cues for stressful episodes. Neurobiology of Learning and Memory, 112, 230-236.

Doi: 10.1016/j.nlm.2013.10.004 